\title{
Elevated Blood Pressure of High Altitude Dwelling Andibila Adults in Oju, Nigeria
}

\author{
Daniel Ter Goon ${ }^{1}$, Charles Mpofu ${ }^{2}$, Vincent Oladele Adeniyi ${ }^{3}$, Uchenna Benedine Okafor ${ }^{1}$, Simon Wuhe Akusu ${ }^{4}$, \\ Benjamin Ijuo Ejeh $^{5} \&$ Unogwu O Unogwu ${ }^{5}$ \\ ${ }^{1}$ Faculty of Health Sciences, University of Fort Hare, East London, South Africa \\ ${ }^{2}$ Faculty of Health and Environmental Sciences, Auckland University of Technology, New Zealand \\ ${ }^{3}$ Department of Family Medicine, Faculty of Health Sciences, Walter Sisulu University/Cecilia Makiwane \\ Hospital, East London Hospital Complex, East London, South Africa \\ ${ }^{4}$ Department of Human Kinetics, Benue State University, Makurdi, Nigeria \\ ${ }^{5}$ Department of Physical and Health Education, College of Education, Oju, Nigeria \\ Correspondence: Daniel Ter Goon, Faculty of Health Sciences, University of Fort Hare, East London, South \\ Africa. E-mail: dgoon@ufh.ac.za
}

Received: August 1, 2018 Accepted: September 18, 2018 Online Published: December 23, 2018

doi:10.5539/gjhs.v11n1p150 URL: https://doi.org/10.5539/gjhs.v11n1p150

\begin{abstract}
Objective: To examine the blood pressure of high altitude dwelling Andibila adults in Oju, Nigeria.

Methods: A cross-sectional survey of 121 Andibila adults living at a high altitude in Oju, Benue state, Nigeria. Body mass, stature, girths (waist and hip circumferences) were taken using standard procedures. Blood pressure (BP) measurement was assessed twice, and the average recorded. Participants with a systolic blood pressure (SBP) of $\geq 140$ and diastolic blood pressure (DBP) of $\geq 90$ were diagnosed as hypertensive.
\end{abstract}

Results: The participants mean age was 49.9 years $(\mathrm{SD}=16.5$. The prevalence rate of elevated pressure was $55.9 \%$. Traditional alcohol use was significantly common in males $(49.1 \%$; OR $=31.8 ; 95 \%$ CI $7.1-143.3 ; \mathrm{p}<0.0001)$ than females $(2.9 \%)$. Increase in SBP was significantly associated with increasing age $(r=0.198 ; \mathrm{p}=0.0301)$, WC $(\mathrm{r}=0.215 ; \mathrm{p}=0.018)$ and $\mathrm{BMI}(\mathrm{r}=0.242 ; \mathrm{p}=0.008)$.

Conclusion: There is need for health education and awareness campaign concerning the risk of elevated blood pressure of lean Andibila adults living in a geographically secluded setting.

Keywords: elevated blood pressure, indigenous population, high altitude, Andibila, Nigeria

\section{Introduction}

Indigenous people are behind everyone, everywhere, concerning their health (Stephens et al., 2005). They face great social disadvantages, poor health and neglect (Bourne, 2003) in national health screening programmes (Hirschler, 2015) compared with the general population (UNDESA, 2004). The lifestyles of traditional communities have generated research interest (Schofield et al., 2014) because it provides an insight into the possible benefits of living a traditional lifestyle dominated by physical activity and unprocessed foods. The Andibila people is one such tribal community that lives in an isolated mountain (350m above sea level) in Nigeria in Oju in the state of Benue. This tribal group, lives a traditional way of life and their day-to-day activities are free from interference from the contemporary Nigerian life with elements of Westernization (Goon, Amusa, Shaw, Shaw, \& Akusu, 2013) Their life is therefore characterized by activities that involve a lot of physical strain fetching wood for energy, food and walking instead of any contemporary means of transport as there are no roads in this community. In addition, there is no modern health and social amenities as well as road networks. Interference from the contemporary Nigerian lifestyle is also limited by difficulty climbing the mountain (Goon, Amusa, Shaw, Shaw, \& Akusu, 2013). The socioeconomic status of this population is lower than that of other Nigerians as measured by income and education level. Perhaps, due to their difficult-to-reach terrain, their health status is undocumented. Such information will provide insight about risk factors of living in highlands. Elevated blood pressure (BP) contributes significantly to global burden of disease and mortality, causing approximately 9.4 million deaths annually (Poulter, Prabhakaran, \& Caulfield, 2015). Elevated BP, a precursor of hypertension is 
associated with the development of many chronic diseases (Khedr et al., 2013). It has been reported that the heart and pulmonary circulation of high altitude dwelling individuals are susceptible to some physiological and morphologic characteristics in relation to chronic hypoxia (Qi, Ma, Jiang, Li, Mai, Chen et al., 2015). The increase in systematic arterial pressure during acute exposure to high altitude, and the accompanying changes in blood pressure have been linked to increase in autonomic and sympathetic activity (Rhodes et al., 2011). The exposure of the lung at high altitude decreases inspired oxygen, thereby triggering hypoxic pulmonary vasoconstriction reflex (Fishman, 2004). Prolonged exposure hypoxia might result to sustain elevated arterial BP and diastolic BP (Hoit, Dalton, Gebremedin, Janocha, Zimmerman, \& Zimmerman, 2011; Wolfel, Selland, Mazzeo, \& Reeves, 1994). However, arterial BP remains normal by enhanced vascularization attributable to decreased total peripheral resistance in adults residing in mountainous regions (Fishman, 2004; Pocock \& Richards, 1999). Again, other studies have reported that inhabitants of high altitude exhibits lower systolic and diastolic BP readings compared to low altitude population (Hoit, Dalton, Gebremedin, Janocha, Zimmerman, \& Zimmerman, 2011; Hanna, 1999; Shrestha, Shrestha, Shrestha, \& Bhattarai, 2012; Tripathy \& Gupta, 2007). Whether this scenario would hold true for the Andibila population residing on a high altitude is speculative. Taken into account the complexity of indignity, risky lifestyles and known risk factors like high altitude living, this study examines the blood pressure of permanent residents of high altitude of rural Andibila, in Oju, Nigeria. Our confirmatory hypothesis would be that the high altitude Andibila population would exhibit 'relative' lower systolic and diastolic BP when compared to other high altitudes population elsewhere.

\section{Methods}

The details regarding the setting, design, sample and sampling procedure of the study has been reported elsewhere (Goon, Adeniyi, Akusu, Ejeh, \& Unogwu, 2017). Briefly, this was a cross-sectional survey of a conveniently sample of 121 Andibila adults residing at high altitude in Oju Local Government Area of Benue State, Nigeria. Ethical approval was sought and obtained from the community chief/elders of Andibila community. Prior to data collection, the aim and nature of the study was explained to the participants for the purpose of getting their verbal consent. Only participants who consented to participate in the study were included. A self-designed questionnaire included information on age, level of education, alcohol consumption, smoking and physical activity participation.

\subsection{Data Collection}

\subsubsection{Anthropometric Measurements}

Anthropometric measurements were measured following the International Society for the Advancement of Kinanthropometry (ISAK) recommendations (Marfell-Jones, Olds, Stew, \& Carter, 2011). All measurements were taken on the right side of the participants. Stature was measured as the perpendicular distance between the vertex of the head and the feet. A calibrated vertical stadiometer (Seca Portable 217 Seca, UK) was used to measure stature to the nearest 0.1 centimetre. The participants were measured in a relaxed and upright position, without footwear or headgear. Body mass was measured in light clothing without shoes using a calibrated digital electronic weighing scale (Seca 813 , Seca, UK) to the nearest 0.1 kilogramme. Body mass index was derived by dividing the body mass in $\mathrm{kg}$ by the stature in meter-square $\left(\mathrm{m}^{2}\right)$.

Girths of the waist and hip was measured with a Lufkin non-extensible flexible anthropometric tape (W606PM, Rosscraft, Canada,) and recorded to the nearest 0.1 centimetre. Waist circumference (WC) was taken with the participant standing, by wrapping the tape at the level of the narrowest point between the lower costal (10th rib) border and the iliac crest. Hip circumference (HC) was measured at the widest diameter of the buttocks, at the level of the greater trochanter. Waist-to-hip ratio (WHR) was derived by dividing the WC by HC. Waist-to-stature ratio (WSR) was derived by dividing the WC by stature.

\subsubsection{Blood Pressure Measurement}

Blood pressure was measured on the right arm, using an OMRON Professional Portable Blood Pressure Monitor (HBP-1300, OMRON, Kyoto, Japan). Measurements were taken after the participants have rested quietly for at least 5 minutes. Both systolic (SBP) and diastolic pressure (DBP) was consecutively measured twice, and the mean recorded. Participants who had a SBP of $\geq 140$ and DBP of $\geq 90$ were classified hypertensive.

\subsection{Data Analysis}

Data was analysed using both descriptive (frequency, percentage, means and standard deviations) and inferential statistics. The association between demographic, anthropometric and cardiovascular variables was investigated in unadjusted analysis and multivariate models. A p-value of 0.05 was set for statistical significant testing. All statistical analyses were carried out using the Statistical Package for Social Sciences (SPSS), version 22.0 for Windows (SPSS Inc., Chicago, IL, USA). 


\section{Results}

Table 1 displays the anthropometric and BP profiles of the participants. The overall prevalence of cigarette smoking, traditional alcohol use and elevated BP were 19.8\% $(\mathrm{n}=24), 23.1 \%(\mathrm{n}=28)$, and $55.9 \%(\mathrm{n}=67)$, respectively (Figure 1). Traditional alcohol use was significantly common in males $(49.1 \%, \mathrm{n}=26 / 53 ; \mathrm{OR}=31.8 ; 95 \%$ CI $7.1-143.3 ; \mathrm{p}<0.0001)$ than females $(2.9 \% \mathrm{n}=2 / 68)$. In bivariate correlation, predicted increase in SBP was significantly associated with increasing levels of age $(r=0.198 ; \mathrm{p}=0.0301)$, WC $(r=0.215 ; \mathrm{p}=0.018)$, and BMI $(\mathrm{r}=0.242 ; \mathrm{p}=0.008)$. In univariate analysis, alcohol intake, cigarette smoking, and BMI were significant potential contributors of arterial hypertension (data not shown).

Table 1. Anthropometric and blood pressure profiles of the participants

\begin{tabular}{lllll}
\hline \multirow{2}{*}{ Variables } & Male $(\mathbf{n}=\mathbf{5 3})$ & Female $(\mathbf{n}=\mathbf{6 8})$ & Total $(\mathbf{n}=\mathbf{1 2 1})$ & \\
\cline { 2 - 5 } & Mean \pm SD & Mean \pm SD & Mean \pm SD & 95\% Confidence Interval \\
\hline Age (years) & $51.9 \pm 19.2$ & $48.4 \pm 14.0$ & $49.9 \pm 16.5$ & $47.0-52.9$ \\
Weight (kg) & $53.0 \pm 7.3$ & $54.18 \pm 11.1$ & $53.6 \pm 9.6$ & $51.9-55.4$ \\
Height (cm) & $161.6 \pm 16.0$ & $156.6 \pm 7.0$ & $158.8 \pm 12.0$ & $156.6-161.0$ \\
BMI (kg.m $\left.{ }^{-2}\right)$ & $22.1 \pm 17.0$ & $22.0 \pm 14$ & $22.1 \pm 11.6$ & $17.8-24.6$ \\
WC (cm) & $76.6 \pm 15.4$ & $76.2 \pm 16.7$ & $76.8 \pm 14.4$ & $76.3-77.6$ \\
WHR & $0.91 \pm 0.28$ & $0.90 \pm 0.12$ & $0.91 \pm 0.36$ & $0.89-0.92$ \\
WSR & $0.49 \pm 0.12$ & $0.48 \pm 0.14$ & $0.49 \pm 0.09$ & $0.47-0.49$ \\
SBP (mmHg) & $141.5 \pm 22.1$ & $148.3 \pm 26.0$ & $145.3 \pm 24.5$ & $140.9-149.7$ \\
DBP (mmHg) & $78.7 \pm 14.2$ & $81.4 \pm 15.2$ & $80.21 \pm 4.8$ & $77.6-82.9$ \\
\hline
\end{tabular}

BMI: Body mass index, WC: Waist circumference, WHR: Waist-to-hip ratio, WSR: Waist-to-stature ratio, SBP: Systolic blood pressure, DBP: Diastolic blood pressure, SD: Standard deviation.

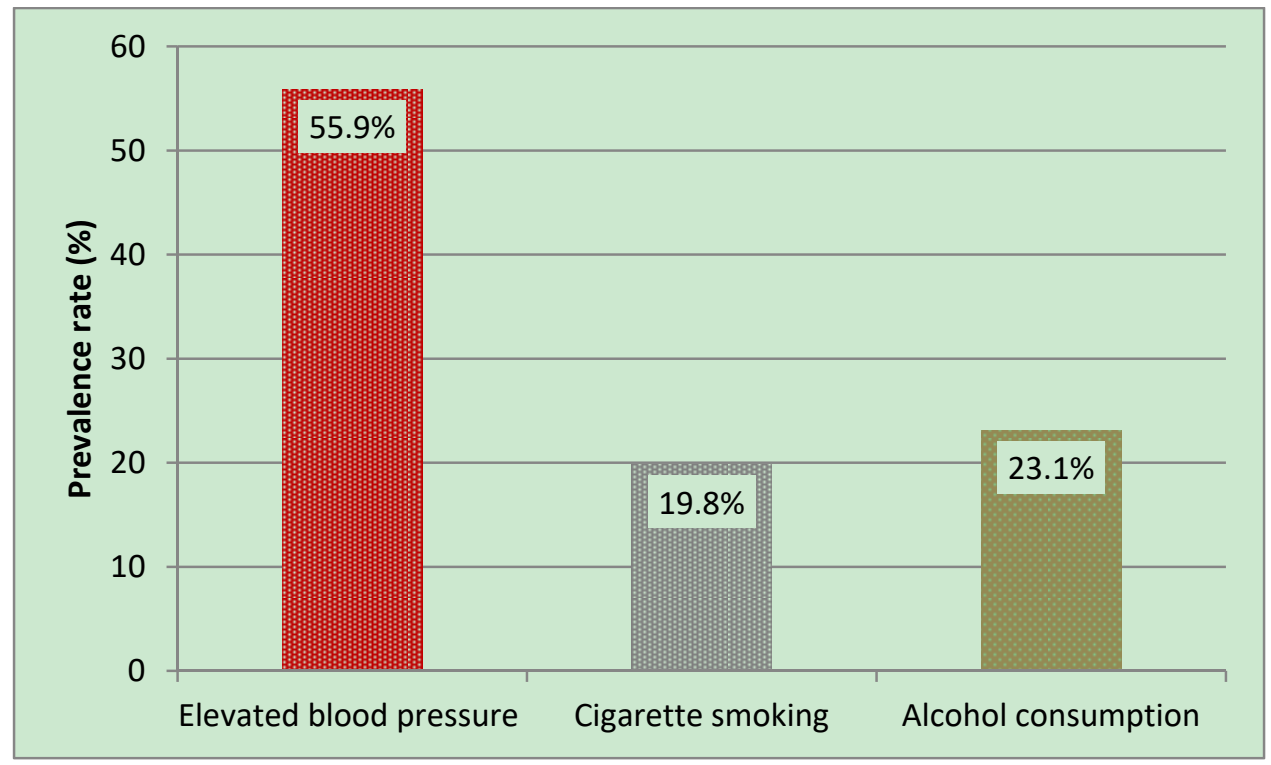

Figure 1. Elevated blood pressure, cigarette smoking and alcohol consumption

\section{Discussion}

This is the first report on elevated BP of Andibila people residing on a high altitude in Oju, Nigeria. This study is important because it provides information on an important health indicator-blood pressure of a under researched and geographically isolated tribal group. There is no basic health and social facilities provided to the Andibila community by the government. From a public perspective, the health information of this tribal, high altitude 
dwelling community, devoid of contemporary modern living is important for policy interventions. There is need to provide health care services and facilities to the Andibila community.

Intriguingly, the elevated BP of Andibila mountain dwellers is high (55.9\%). Other researchers has reported high prevalence of hypertension among the lean Eritrean (Usman, Mebrahtu, Debru, Tesfazion, Gebresellasie, \& Ghebrat, 2015) and Chinese (Nguyen, Adair, He, \& Popkin, 2008) population. Arterial hypertension is known to be affected by heredity (age, race, gender), and lifestyle behaviour (smoking, obesity, alcohol consumption, physical inactivity, stress, and excessive salt intake). It is possible that the high elevated BP of among the Andibila people could be attributed to the type of community they live and perhaps affected by the unique mountainous (high altitude) challenges they encounter. Cultural beliefs and practices, as well as genetics could be possible risk factors for the elevated BP among the Andibila community. Norboo et al. (2015) study reported age, gender, socio-economic variables and changing lifestyle behaviours as correlates of hypertension among high altitude residents. It should be noted that at the time of conducting BP measurements among our sample, those with elevated BP were asked if they have ever being told about their BP levels; and whether they used too much salt for their food, most of the participants affirmed being diagnosed with high blood pressure and indicated taking some medications as well as adding too much salt to their food. Intuitively, the consumption of salt is high among the population. Besides, the consumption of alcohol and smoking of local tobacco among the Andibila people is a common traditional practice. These provide evidences for the elevated BP found our sample in this setting.

\section{Limitations}

The small sample size of the participants limits generalisability, as well as age and sex statistical analyses. Second, a BP measurement at a single visit usually overestimates hypertension prevalence. Thus, in this paper, we use the term 'elevated BP' rather than 'hypertension. Third, information was not collected on other variables such as dietary habits, blood lipids and blood glucose, which are relevant to elevated blood pressure aetiology. Therefore, we cannot rule out the possibility that our findings might have been somewhat biased by the lack of these important confounders. Future studies should endeavour to assess these variables in order to clearly understand the complexity of the elevated BP levels of this high altitude population, and to enable proper intervention and treatment programmes. Despite these limitations, this study has made an inroad in documenting the nuance of health-elevated BP among a secluded and neglected indigenous Andibila people.

\section{Conclusion}

Given the elevated BP found among the Andibila community living in an isolated, rural and mountainous setting, appropriate intervention strategies should be instituted by the Oju local government to prevent and control elevated BP among this tribal group by increasing awareness about regular check-up of BP, regular exercise, reduce salt intake, and abstinence from alcohol and smoking. The Andibila people, as part of the larger Oju community, deserve attention and care.

\section{Competing Interests Statement}

The authors declare that there are no competing or potential conflicts of interest.

\section{References}

Bourne, R. (2003). Plight of indigenous peoples in the Commonwealth. Commonwealth Policy Studies Unit, London, Invisible lives. Undercounted, underrepresented and underneath: the socio-economic.

Fishman, A. P. (2004). Acute hypoxia and pulmonary vasoconstriction in humans: uncovering the mechanism of the pressor response. American Journal of Physiology, Lung Cells and Molecular Physiology, 287, L893-L894. https://doi.org/10.1152/classicessays.00004.2004

Goon, D. T., Adeniyi, O. V., Akusu, S. W., Ejeh, B. I., \& Unogwu, U. O. (2017). Low body mass index of indigenous Andibila community residing at high altitude in Oju, Nigeria: Who cares? Pakistan Journal of Nutrition, 16(7), 557-651. https://doi.org/10.3923/pjn.2017.557.561

Hanna, J. M. (1999). Climate altitude and blood pressure. Human Biology, 71(4), 553-582.

Hirschler, V. (2015). Cardiometabolic risk factors in native populations living at high altitudes. International Journal of Clinical Practice, 70, 113-118. https://doi.org/10.1111/ijcp.12756

Hoit, B. D., Dalton, N. D., Gebremedin, A., Janocha, A., Zimmerman, P. A., \& Zimmerman, A. M. (2011). Elevated pulmonary artery pressure among Amhara highlanders in Ethiopia. American Journal of Human Biology, 23, 168-176. https://doi.org/10.1152/japplphysiol.00394.2016

Khedr, E. M., Elfetoh, N. A., Al Attar, G., Ahmed, M. A., Ali, A. M., Hamdy, A., Kandil, M. R., \& Farweez, H. 
(2013). Epidemiological study and risk factors of stroke in Assiut Governorate, Egypt: Community-based study. Neuroepidemiology, 40(4), 288-294. https://doi.org/10.1159/000346270

Nguyen, T. T., Adair, L. S., He, K., \& Popkin, B. M. (2008). Optimal cut-off values for overweight: using body mass index to predict incidence of hypertension in 18-65 year old Chinese adults. Journal of Nutrition, 138(7), 1377-1383. https://doi.org/10.1093/jn/138.7.1377

Norboo, T., Stobdan, T., Tsering, N., Angchuk, N., Tsering, P., Ahmed, I., ... \& Kimura, Y. (2015). Prevalence of hypertension at high altitude: cross-sectional survey in Ladakh, Northern India 2007-2011. BMJ open, 5(4), e007026. https://doi.org/10.1136/bmjopen-2014- 007026

Pocock, G., \& Richards, C. D. (1999). Human physiology: the basis of medicine. Oxford: Oxford University Press, 591-598.

Poulter, N. R., Prabhakaran, D., \& Caulfield, M. (2015). Hypertension. Lancet, 386(9995), 801-812. https://doi.org/10.1016/S0140-6736(14)61468-9

Qi, H. Y., Ma, R. Y., Jiang, L. X., Li, S. P., Mai, S., Chen, H., ... \& Xu, S. Y. (2015). Anatomical and hemodynamic evaluations of the heart and pulmonary arterial pressure in healthy children residing at high altitude in China. IJC Heart \& Vasculature, 7, 158-164. https://doi.org/10.1016/j.ijcha.2014.10.015

Marfell-Jones, M., Olds, T., Stew, A., \&. Carter, L. (2011). International standards for anthropometric assessment. Australia: The International Society for the Advancement of Kinanthropometry.

Rhodes, H. I., Chesterman, K., Chan, C. W., Collins, P., Kewley, E., \& Pattinson, K. T. (2011). Systemic blood pressure, arterial stiffness and pulse waveform analysis at altitude. Journal of Royal Army Medical Corps, 157(1), 110-113. https://doi.org/10.1136/jramc-157-01-18

Schofield, G., Zinn, C., Harris, N., Williden, M., Crofts, C., Thornley, S. et al. (2014). Response to Draft Dietary Guidelines Submitted to the Ministry of Health.

Shrestha, S., Shrestha, A., Shrestha, S., \& Bhattarai, D. (2012). Blood pressure in inhabitants of high altitude of Western Nepal. Journal of Nepal Medical Association, 52(188), 154-158. https://doi.org/10.31729/jnma.371

Stephens, C., Nettleton, C., Porter, J., Willis, R., \& Clark, S. (2005). Indigenous peoples' health-why are they behind everyone, everywhere? Lancet, 366, 10-12. https://doi.org/10.1016/S0140-6736(05)66801-8

Tripathy, V., \& Gupta, R. (2007). Blood pressure variation among Tibetans at different altitudes. Annals of Human Biology, 34(4), 470-483. https://doi.org/10.1080/03014460701412284

UNDESA. (2015). State of the World's Indigenous Peoples. United Nations Department of Economic and Social Affairs, New York.

UNDESA. (2004). The concept of indigenous peoples. United Nations Department of Economic and Social Affairs, New York.

Usman, A., Mebrahtu, G., Debru, B., Tesfazion, A., Gebresellasie, A., Ghebrat, Y. et al. (2015). Complex relationships between body mass index and blood pressure in a lean population in Eritrea. Jacobs Journal of Obesity, 1(3), 1-20.

Wolfel, E. E., Selland, M. A. M., Mazzeo, R. S., \& Reeves, J. T. (1994). Systematic hypertension at 4300m is related to sympathoadrenal activity. Journal of Applied Physiology, 76(4), 1643-1650. https://doi.org/10.1152/jappl.1994.76.4.1643

\section{Copyrights}

Copyright for this article is retained by the author(s), with first publication rights granted to the journal.

This is an open-access article distributed under the terms and conditions of the Creative Commons Attribution license (http://creativecommons.org/licenses/by/4.0/). 